\title{
Introduction to Problem Solving Using a Monte Carlo Spreadsheet Simulation
}

\author{
David Greenburg \\ The CITADEL School of Engineering \\ Dimitra Michalaka
The CITADEL School of Engineering \\ James Righter \\ The CITADEL School of Engineering
}

\begin{abstract}
At The Citadel, data collection, analysis, and problem solving is taught as part of the technical project management course for junior and senior engineering students. Many real world problems have such a broad scope or are so complicated that they resist a purely analytical solution. One technique for analyzing these complex problems is simulation. This paper describes the efforts to introduce students to spreadsheetbased Monte Carlo simulation modeling to support problem solving. Students can master spread-sheetbased simulation especially easily, and can expand their skill set by being taught to use real world data sets. The instruction introduces students to spreadsheet modeling with excel software and the fundamental aspects of data collection, analysis, and simulation modeling. The instruction aims to provide students with modeling skills to support problem solving. Students can master spread-sheet-based Monte Carlo simulation, and can expand their skill set by doing so. This paper describes the use of spreadsheet-based Monte Carlo simulation and briefly explores the underlying methodology using Excel to support the instruction.
\end{abstract}

Keywords: forecasting, Monte Carlo Simulation, data analysis

\section{INTRODUCTION}

Simulation is a useful technique to address real world system problems in order to obtain data that can be used to make predictions about the system. Monte Carlo simulation involves the collection of historical data and the development of frequency distributions to support probabilistic analysis to make inferences about the system being studied. Project planning is an important activity that involves the careful study of historic data to project future demand outcomes. In many situations, engineering managers have access to a good deal of historical data which can be used to develop forecasts for the future. This paper discusses the development of a module to introduce the use of Monte Carlo Simulation to aid in project planning, forecasting and decision making. This paper describes our approach to incorporate simulation modeling as part of a technical project management course for undergraduate engineering students. The instruction is designed to complement two existing courses (PMGT 401 and CIVL 305). Due to the availability and ease of learning Excel software can be used to complement lectures and homework assignments. 
Engineers are often involved in the management of projects that require the scheduling of constrained resources to include labor, equipment and materials and other activities relating to the project. Scheduling is a central and integral process for effective technical project management ${ }^{1}$. The success of any technical project is judged by how well it achieves a defined outcome for cost, schedule, and performance ${ }^{2}$. Most projects would not be undertaken if management had little confidence in a successful outcome and once started are subject to being cancelled if the forecasted outcome does not meet expectations.

\section{Monte Carlo Simulation Relevance}

Monte Carlo Simulation is an important tool for decision-making as it deals with the collection, analysis and use of historical data to make future estimates that are used in making decisions and solving problems ${ }^{3}$. It can be used by technical project managers to forecast the occurrence of outcomes when random variables are present. These simulations use random number generators to simulate random effects and gain knowledge just as we would if we took many samples of a real event. The wide availability of computers allows us to easily perform simulation and integrate its use into the curriculum.

Our approach to teaching Monte Carlo Simulation emphasizes sound data collection approaches by introducing students to readily available primary sources of raw data. One such source is the South Carolina (SC) Traffic Polling and Analysis System (TPAS) which provides near real-time traffic count information at over 160 Continuous Count Stations (CCS) statewide ${ }^{4}$. These stations collect hourly traffic volume data through permanent sensors installed in the roadway. Faculty have previously used TPAS data to teach students statistical forecasting techniques ${ }^{5}$. Students are shown how to access the TPAS and download an excel data file containing raw data for a specified period. An example of the data available is shown in Figure 1.

FIGURE 1

\section{SC DOT TPAS DATA FOR CCS 0142}

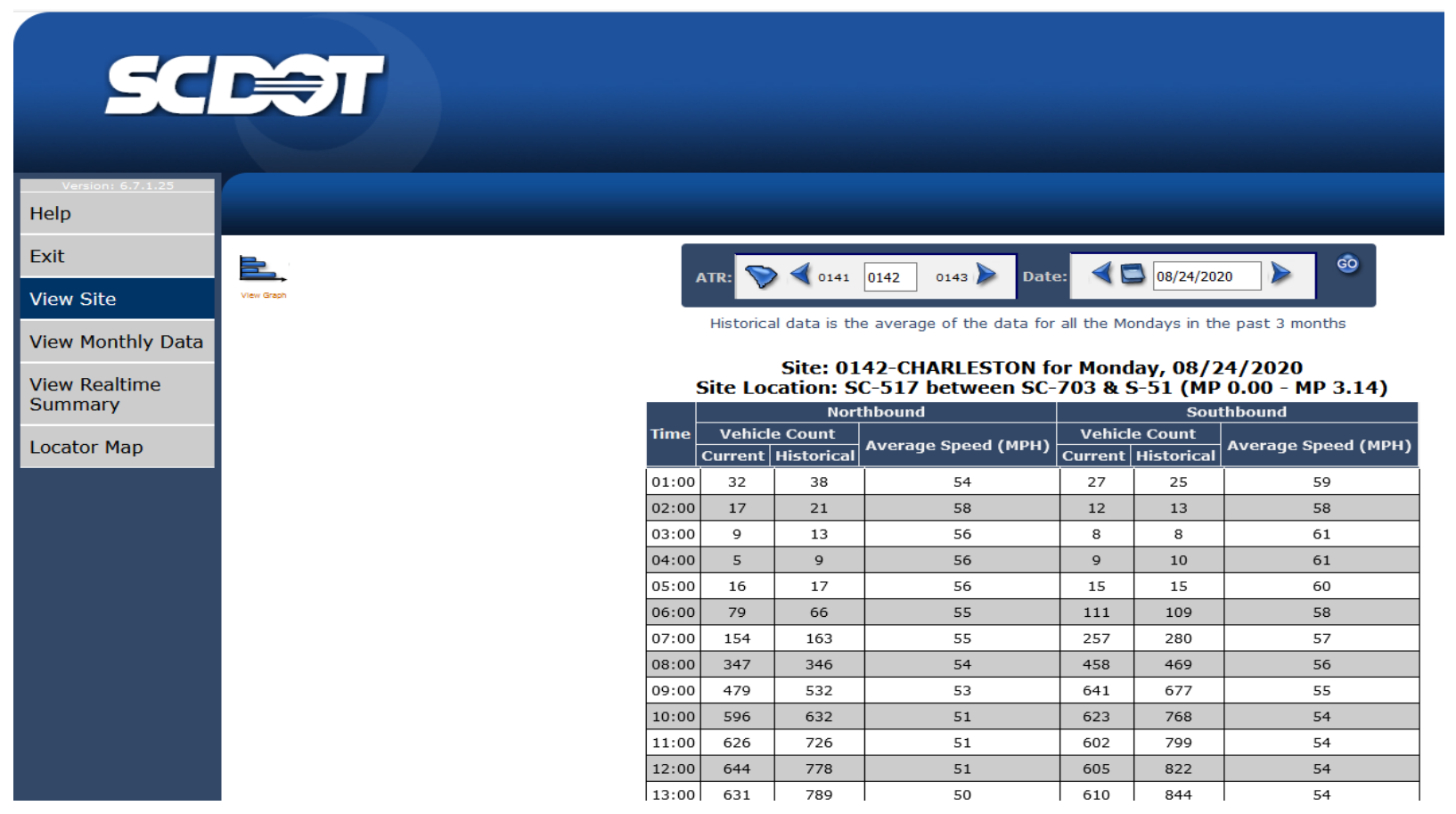

Students are asked to download data for a specific time interval to use in developing cumulative probability distributions for modeling future traffic flow. This paper describes how we teach students to use Monte Carlo simulation using Excel spread sheets and common built in functions to aid in problem solving and decision making. 


\section{Developing a Monte Carlo Model}

The Monte Carlo method incorporates the development of a cumulative frequency distribution based on collected historical data. By generating a table of random numbers to simulate values and fitting them to the expected frequency distribution we can use the random numbers to forecast the possible outcomes of an uncertain event. Excel is an ideal tool to generate random numbers to simulate variables of interest such as traffic flow. Generating a large number of random variables allows us to simulate a variable's behavior. This process is repeated again and again while assigning the variable in question with many different values. Once the simulation is complete, the results are averaged together to provide an estimate. Our Monte Carlo simulation example problem models predicted future traffic counts for a specific road section in need of maintenance. The problem statement presented to the students asks them to plan the optimum time to shut down a section of SC Highway 517 for needed road maintenance that will take 3 hours from start to finish. The measure of optimality being the lowest traffic count for a specific time of day in order to minimize disruption to traffic flow. Students are advised to follow the following steps:

1. Collect historical source data and identify the variables of interest which include traffic counts for the following specific time periods:
a. $00: 00-02: 59$
b. $03: 00-05: 59$
c. $06: 00-08: 59$
d. $09: 00-11: 59$
e. $12: 00-14: 59$
f. $15: 00-17: 59$
g. $18: 00-20: 59$
h. $21: 00-23: 59$

2. Build a cumulative probability distribution for each variable being modeled like the one shown in Table 1. SC TPAS data is analyzed to determine the relative frequency of traffic flow during each time period. The probability of each outcome is found by dividing the frequency of observation by the total flow.

TABLE 1

PROBABILITY DISTRIBUTION FOR THE FASIMULATED TRAFFIC COUNT

\begin{tabular}{ccccc}
\hline Frequency & $\begin{array}{c}\text { Probability of } \\
\text { Occurrence }\end{array}$ & $\begin{array}{c}\text { Cumulative } \\
\text { Probability }\end{array}$ & $\begin{array}{c}\text { Random Number } \\
\text { Intervals }\end{array}$ & $\begin{array}{c}\text { Simulated Traffic } \\
\text { Count }\end{array}$ \\
43 & 0.006 & 0.006 & $0-6$ & 59 \\
44 & 0.006 & 0.012 & $7-12$ & 66 \\
733 & 0.102 & 0.114 & $13-114$ & 1030 \\
1444 & 0.201 & 0.315 & $115-315$ & 2023 \\
1654 & 0.230 & 0.545 & $316-545$ & 2283 \\
1754 & 0.244 & 0.789 & $546-789$ & 2447 \\
1193 & 0.166 & 0.954 & $790-954$ & 1642 \\
328 & 0.046 & 1.000 & $955-1000$ & 450 \\
\hline 7193 & 1.00 & & & 10000 \\
\hline
\end{tabular}

3. Establish random number intervals to represent the range of possible traffic counts for each time period.

Use the RANDBETWEEN function in Microsoft Excel to create tables of 10,000 random integers to simulate traffic flow. Excel 2016 uses a very high quality algorithm, which has been shown by NIST to be suitable for samples of up to $10^{136}$. 
FIGURE 2

SIMULATED FREQUENCY DISTRIBUTION AND ESTIMATES

\begin{tabular}{|c|c|c|c|c|c|c|c|c|c|c|c|}
\hline \multicolumn{2}{|c|}{ M12 } & \multirow{2}{*}{ D } & $\checkmark \quad f_{\boldsymbol{x}}$ & \multicolumn{7}{|c|}{$=$ COUNTIFS('Rand\#1'!\$A\$1:\$A\$10000,">=0",'Rand\#1'!\$A\$1:\$A $\$ 10000, "<=6 ")$} & \multirow[b]{2}{*}{$\mathrm{M}$} \\
\hline 4 & $\mathrm{C}$ & & $\mathrm{E}$ & $\mathrm{F}$ & G & $\mathrm{H}$ & 1 & J & K & L & \\
\hline 10 & Current & Historical & $\begin{array}{l}\text { Average } \\
\text { Speed } \\
\text { (MPH) }\end{array}$ & Current & Historical & $\begin{array}{l}\text { Average } \\
\text { Speed } \\
\text { (MPH) }\end{array}$ & Frequency & $\begin{array}{l}\text { Probability of } \\
\text { Occurrence }\end{array}$ & $\begin{array}{l}\text { Cumulative } \\
\text { Probability }\end{array}$ & $\begin{array}{l}\text { Random } \\
\text { Number } \\
\text { Intervals }\end{array}$ & $\begin{array}{l}\text { Simulated } \\
\text { Traffic } \\
\text { Count }\end{array}$ \\
\hline 11 & 12 & 25 & 48 & 13 & 16 & 44 & \multirow{3}{*}{43} & \multirow{3}{*}{0.006} & & & \\
\hline 12 & 14 & 12 & 48 & 8 & 8 & 57 & & & 0.006 & $0-6$ & 59 \\
\hline 13 & 4 & 6 & 49 & 6 & 6 & 47 & & & & & \\
\hline 14 & 10 & 5 & 48 & 0 & 4 & N/A & \multirow{3}{*}{44} & \multirow{3}{*}{0.006} & & & \\
\hline 15 & 7 & 12 & 47 & 9 & 10 & 47 & & & 0.012 & $7-12$ & 66 \\
\hline 16 & 29 & 27 & 47 & 34 & 43 & 45 & & & & & \\
\hline 17 & 96 & 101 & 48 & 153 & 146 & 47 & \multirow{3}{*}{733} & \multirow{3}{*}{0.102} & & & \\
\hline 18 & 259 & 229 & 47 & 310 & 333 & 46 & & & 0.114 & $13-114$ & 1030 \\
\hline 19 & 379 & 403 & 45 & 485 & 492 & 44 & & & & & \\
\hline 20 & 417 & 443 & 45 & 417 & 495 & 45 & \multirow{3}{*}{1444} & \multirow{3}{*}{0.201} & & & \\
\hline 21 & 419 & 478 & 45 & 401 & 486 & 45 & & & 0.315 & $115-315$ & 2023 \\
\hline 22 & 400 & 523 & 44 & 389 & 535 & 46 & & & & & \\
\hline 23 & 512 & 575 & 42 & 432 & 609 & 45 & \multirow{3}{*}{1654} & \multirow{3}{*}{0.230} & & & \\
\hline 24 & 450 & 529 & 44 & 453 & 573 & 45 & & & 0.545 & $316-545$ & 2283 \\
\hline 25 & 458 & 550 & 45 & 433 & 526 & 46 & & & & & \\
\hline 26 & 532 & 600 & 43 & 430 & 527 & 44 & \multirow{3}{*}{1754} & \multirow{3}{*}{0.244} & & & \\
\hline 27 & 507 & 612 & 45 & 466 & 521 & 45 & & & 0.789 & $546-789$ & 2447 \\
\hline 28 & 377 & 542 & 46 & 468 & 535 & 46 & & & & & \\
\hline 29 & 335 & 436 & 45 & 370 & 481 & 46 & \multirow{3}{*}{1193} & \multirow{3}{*}{0.166} & & & \\
\hline 30 & 292 & 392 & 41 & 228 & 354 & 45 & & & 0.954 & $790-954$ & 1642 \\
\hline 31 & 103 & 365 & 42 & 103 & 212 & 44 & & & & & \\
\hline 32 & 81 & 188 & 44 & 67 & 107 & 45 & \multirow{3}{*}{328} & \multirow{3}{*}{0.046} & & & \\
\hline 33 & 58 & 96 & 46 & 31 & 51 & 46 & & & 1.000 & $955-1000$ & 450 \\
\hline 34 & 16 & 44 & 49 & 19 & 25 & 48 & & & & & \\
\hline 35 & & & & & & & 7193 & 1.00 & & & 10000 \\
\hline \multirow[t]{2}{*}{$s e$} & & & & & & & & & & & \\
\hline & b & 82420 & Rand\#1 & 82520 & Rand\#2 & 82620 & Rand\#3 & 82720 & 82820 & Rand\#5 & † \\
\hline
\end{tabular}

Pressing F9 on the keyboard will generate new random number values for a new simulation. Students can press F9 a few times and watch the traffic flow estimates change as well as their associated plots shown in Figure 3.

FIGURE 3

\section{PLOTS OF SIMULATED TRAFFIC FLOW}

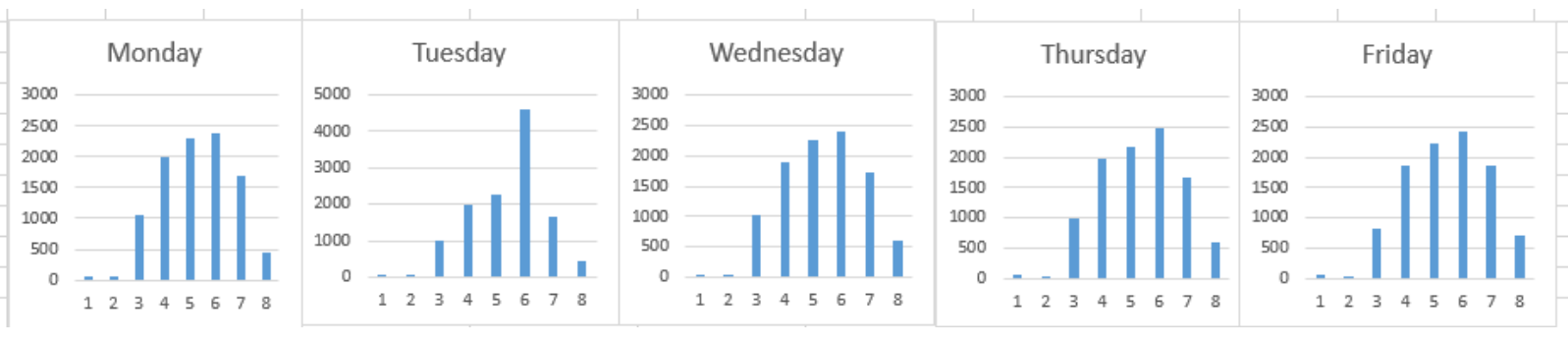

Journal of Strategic Innovation and Sustainability Vol. 16(2) 2021161 
Figure 3 shows the results of daily traffic count simulations based on a flow of 10,000 vehicles occurring the three-hour time periods for each day. Students are next asked to analyze and interpret the expected traffic flows and make a recommendation as to which time period on which day is the least intrusive time to close the road and conduct maintenance. Students were generally able to quickly master the basic concepts of Monte Carlo simulation using Excel and gained confidence in gathering data and incorporating modeling to aid in analysis and decision making. Based on positive feedback from the students we intend to introduce more modeling based assignments in future courses.

\section{CONCLUSIONS}

Informed decision-making plays a crucial role in the effective management of every project. Employing Monte Carlo Simulation techniques is an easy way to reduce risks and make important decisions. Having a good knowledge of simulation techniques can play an important role in the management and operations of technical projects ${ }^{7}$. This introduction to Monte Carlo Simulation provides students with the knowledge and practical experience in building useful predictive models using readily available excel software. By focusing on the concepts of valid data collection, model building, analysis, interpretation, and presentation vice the mechanics of calculation students gain abilities and confidence needed to solve realistic problems.

\section{ENDNOTES}

1. Hildreth, J. C. and Munoz, B. P. (2005). An Introduction to the Management Principles of Scheduling, TR05-04, A report presented to the Virginia Department of Transportation and the VDOT-VT Partnership for Project Scheduling Advisory Board.

2. Jones, E. F. (2009). Scheduling 101-the basic of best practices. Paper presented at PMI ${ }^{\circledR}$ Global Congress 2009-North America, Orlando, FL. Newtown Square, PA: Project Management Institute.

3. T. J. Schriber, T. J., "Simulation for the masses: Spreadsheet-based Monte Carlo simulation," Proceedings of the 2009 Winter Simulation Conference (WSC), Austin, TX, USA, 2009, pp. 1-11, doi: 10.1109/WSC.2009.5429310.

4. SCDOT Traffic Polling and Analysis System, http://dbw.scdot.org/Poll5WebAppPublic/wfrm/wfrmHomePage.aspx._Accessed July 17, 2018.

5. Greenburg, D. and Righter, J. (2020), "Introduction To Forecasting Methods For Engineering Students Using R," Proceedings of the American Society of Engineering Education, Southeastern Section Annual Conference.

6. https://www.engineering.com/AdvancedManufacturing/ArticleID/18106/Introduction-to-Monte-CarloSimulation.aspx

7. Subramanyan, H. and K Moorthy, K. (2016) Designing and Evaluating Simulation Games For Professional Project Management Education. 2016 Project management Symposium, University of Maryland. 